\title{
Interrupted Etanercept Therapy: A New Case Report
}

\author{
Waqas S. Abdulwahhab1,2, Alaa S. Mehair ${ }^{1}$ \\ ${ }^{1}$ Department of Dermatology and Venereology, Al Qassimi Hospital, Sharjah, United Arab Emirates \\ ${ }^{2}$ College of Medicine, University of Sharjah, Sharjah, United Arab Emirates \\ Email: wqs_saad@yahoo.com, alaa.alazawe@yahoo.com
}

How to cite this paper: Abdulwahhab, W.S. and Mehair, A.S. (2021) Interrupted Etanercept Therapy: A New Case Report. Journal of Cosmetics, Dermatological Sciences and Applications, 11, 71-75. https://doi.org/10.4236/jcdsa.2021.112007

Received: February 18, 2021

Accepted: April 12, 2021

Published: April 15, 2021

Copyright () 2021 by author(s) and Scientific Research Publishing Inc. This work is licensed under the Creative Commons Attribution International License (CC BY 4.0).

http://creativecommons.org/licenses/by/4.0/

(c) (i) Open Access

\begin{abstract}
Psoriasis is a chronic, immune-mediated, inflammatory disease with a high prevalence in the general population (2\%). The anti-tumor necrosis factor receptor etanercept is Food and Drug Administration (FDA) approved for the treatment of moderate-to-severe plaque psoriasis. Both continuous and interrupted etanercept therapy is effective and well-tolerated. This report aims to document a new case presentation of psoriasis on intermittent etanercept injection throughout 36 weeks with long-lasting sustained efficacy and no risk factor. Case Report: A 39-year-old adult male patient with long-standing chronic plaque psoriasis for 15 years duration without joint involvement started loading dose treatment of etanercept injection in whom due to his work circumstances not taken maintenance therapy and showed-up at the clinic after 36 weeks from first induction therapy when partial relapse of psoriatic lesions appear in last week with continued improvement when re-introducing loading treatment on followed-up over the next 36 weeks. Conclusion: Intermittent etanercept therapy considers effective for 36 weeks with prolonging sustained efficacy and without adverse effect.
\end{abstract}

\section{Keywords}

Adherence, Anti-Tumor Necrosis Factor-Alpha (Anti-TNF- $\alpha$ ), Etanercept, Interrupted Therapy, Psoriasis

\section{Introduction}

Psoriasis is a chronic, immune-mediated, inflammatory disease with a high prevalence in the general population (2\%) and an important impact on the quality of life [1].

Treatment adherence to anti-tumor necrosis factor-alpha (anti-TNF- $\alpha$ ) agents 
is an overall marker of treatment success, and it depends on multiple factors, such as efficacy, safety profile, patient satisfaction, and physician's confidence with the drug used. Clinical trials and registries indicated that the overall efficacy of anti-TNF- $\alpha$ decreases over time leading to a progressive loss of patient adherence to treatment. Studies have revealed that the major reason for treatment discontinuation is the loss of efficacy, followed by adverse events [2] [3] [4] [5] [6].

The soluble tumor necrosis factor receptor etanercept is approved by the FDA for the treatment of moderate to severe plaque psoriasis [7].

In real-world experience, patients and practicing dermatologists may opt to use etanercept intermittently for various reasons, including interruptions in insurance coverage or preparation for surgery. A recent study demonstrated control of psoriasis symptoms after discontinuation and re-treatment with etanercept [8].

In the present case report, we are describing a 39-year-old adult male with a long-standing history of chronic plaque psoriasis who improved and sustained efficacy on just loading injection of etanercept therapy for 36 weeks followed-up. The consent form was taken from the patient about the publication of his condition.

\section{Case Report}

A 39-year-old adult male patient presented to our clinic with long-standing, severe plaque psoriasis for 15 years duration without joint involvement. For several years, he received multiple appropriate topical therapies (e.g. tar, topical corticosteroids, and vitamin D analogs), and narrowband UVB phototherapy but remained refractory to treatment. He was initially treated with $15 \mathrm{mg}$ per week oral methotrexate, which resulted in significant improvement.

However, abnormal findings in liver functions were noted, unfortunately, leading to discontinuation.

On examination, the patient had diffuse erythematous, inflammatory plaques covered with adherent white silvery scales involving $25 \%$ of the body surface area (BSA) and psoriasis area and severity index (PASI) score of 13. Biological therapy was recommended and induction treatment with etanercept was initiated with $50 \mathrm{mg}$ twice weekly for the first 12 weeks. On follow-up, after 8 weeks disease was stabilized, with mild erythema involving $1 \%$ of BSA, a PASI score of 1.3 .

Due to his work circumstances, he did not show up to his scheduled follow-up after the finished induction dose. However, he came after 36 weeks from the first induction dose of etanercept when the disease relapsed involving mostly the lower legs and on examination, PASI score was 7.2 and BSA 12\%. According to the patient, this relapse started last week (Figure 1).

Thus, full patient screening was done for safety and for discovering any hidden disorder including complete blood count, erythema sediment rate, C-reactive 
protein, lactate dehydrogenase, liver function test, lipid profile, electrolyte panel, QuantiFERON-TB GOLD blood test, chest x-ray and resulted with no risk factors could appear. Re-treatment with the same induction dose of etanercept was given and instructs the patient coming back for follow up after one month to assess the improvement, but he came again after 36 weeks from the first injection showed sustained efficacy and no side effect and on examination, PASI score was 1.3 and BSA 1\% (Figure 2). The recommendation is given to the patient to follow up monthly for any signs of relapse and continuing on just topical moisturization.

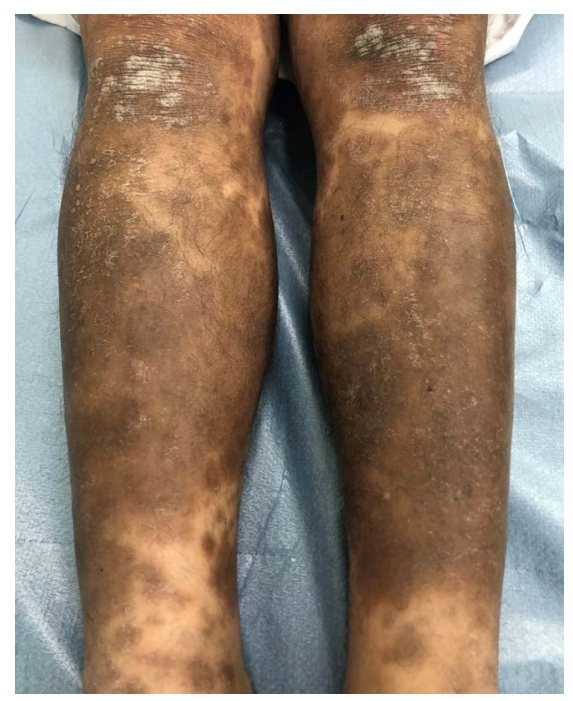

Figure 1. 36 weeks followed up after the first induction dose of etanercept injection showed relapsed psoriatic plaques involving both knee joints and Lower legs associated with diffuse post-inflammatory hyperpigmentation in a 39-year-old adult male.

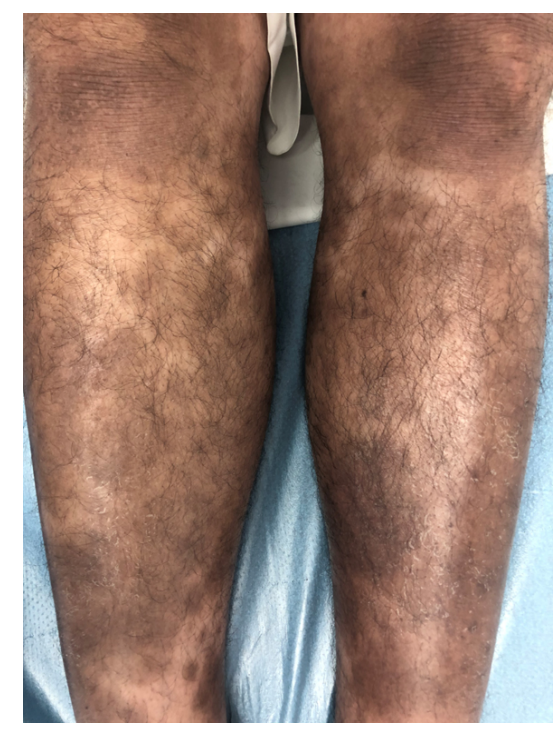

Figure 2. 36 weeks followed up psoriasis after the second induction dose of etanercept injection showed sustained improvement. Note post-inflammatory hyperpigmentation and fine scales involving both knee joints and lower legs in a 39-year-old adult male. 


\section{Discussion}

In some studies that compare continuous and interrupted etanercept therapy, both the results were effective and well-tolerated in patients with psoriasis, with greater improvements observed in the continuous arm at week 24 and most patients regained their response after re-initiation of etanercept [9]. While in other reports, treatment survival was constantly high in patients going intermittent regimen with optimal clinical success and adherence [6].

Psoriasis is commonly a chronic disease that requires continuous treatment. However, for some patients, it is characterized by more extended periods of remission and intermittent relapse. In the clinical setting, interruption of therapy may occur for reasons such as disease remission, discontinuation of insurance coverage, cost-effectiveness, concurrent disease, intercurrent illness, or preparation for surgery. The risks involved in stopping and restarting therapy are relapse, rebound, or tachyphylaxis and inability to regain efficacy [10]. In our case report, the reason for restart medication is the relapse of disease after a prolonged remission period.

Etanercept was initially approved in European countries for patients with psoriasis only with intermittent schedules up to 24 weeks, with re-treatment after treatment interruption in case of disease recurrence [6]. In our report, the intermittent therapy is prolonged up to 36 weeks and the disease was controlled with sustained efficacy and without any serious infection or adverse effect observed.

This study added to other studies that discuss continuous and intermittent etanercept therapy [6] [9].

In conclusion, intermittent etanercept treatment of the patient with moderate to severe plaque psoriasis is safe, well-tolerated, and efficacious after induction dose for 36 weeks without adverse effect.

However further studies are required involving more patients, to assess the response to these prolonged remission periods.

\section{Conflicts of Interest}

The authors declare no conflicts of interest regarding the publication of this paper.

\section{References}

[1] Menter, A, Korman, N.J., Elmets, C.A., et al. (2011) Guidelines of Care for the Management of Psoriasis and Psoriatic Arthritis: Section 6. Guidelines of Care for the Treatment of Psoriasis and Psoriatic Arthritis: Case-Based Presentations and Evidence-Based Conclusions. Journal of the American Academy of Dermatology, 65, 137-174. https://doi.org/10.1016/j.jaad.2010.11.055

[2] Glintborg, B., Østergaard, M., Dreyer, L., Krogh, N.S., Tarp, U., Hansen, M.S., Rifbjerg-Madsen, S., Lorenzen, T. and Hetland, M.L. (2011) Treatment Response, Drug Survival, and Predictors in 764 Patients with Psoriatic Arthritis Treated with Anti-Tumor Necrosis Factor a Therapy: Results from the Nationwide Danish Danbio Registry. Arthritis \& Rheumatology, 63, 382-390. https://doi.org/10.1002/art.30117 
[3] Gniadecki, R., Kragballe, K., Dam, T.N. and Skov, L. (2011) Comparison of Drug Survival Rates for Adalimumab, Etanercept, and Infliximab in Patients with Psoriasis Vulgaris. British Journal of Dermatology, 164, 1091-1096.

https://doi.org/10.1111/j.1365-2133.2011.10213.x

[4] Brunasso, A.M., Puntoni, M. and Massone, C. (2012) The Drug Survival Rate of Biologic Treatments in Patients with Psoriasis Vulgaris. British Journal of Dermatology, 166, 447-449. https://doi.org/10.1111/j.1365-2133.2011.10557.x

[5] Esposito, M., Gisondi, P., Cassano, N., Ferrucci, G., Del Giglio, M., Loconsole, F., Giunta, A., Vena, G.A., Chimenti, S. and Girolomoni, G. (2013) Survival Rate of Antitumour Necrosis Factor- $\alpha$ Treatments for Psoriasis in Routine Dermatological Practice: A Multicentre Observational Study. British Journal of Dermatology, 169, 666-672. https://doi.org/10.1111/bjd.12422

[6] Esposito, M., Gisondi, P., Cassano, N., Babino, G., Cannizzaro, M.V., Ferrucci, G., Chimenti, S. and Giunta, A. (2014) Treatment Adherence to Different Etanercept Regimens, Continuous vs. Intermittent, in Patients Affected by Plaque-Type Psoriasis. Drug Development Research, 75, S31-S34. https://doi.org/10.1002/ddr.21190

[7] (2006) EnbrelÒ (Etanercept) [Prescribing Information]. Amgen Inc. and WyethAyerst Pharmaceuticals, Thousand Oaks, CA.

[8] Gordon, K.B., Gottlieb, A.B., Leonardi, C.L., Elewski, B.E., Wang, A., Jahreis, A., et al. (2006) Clinical Response in Psoriasis Patients Discontinued from and then Reinitiated on Etanercept Therapy. Journal of Dermatological Treatment, 17, 9-17. https://doi.org/10.1080/09546630500472838

[9] Moore, A., Gordon, K.B., Kang, S., Gottlieb, A., Freundlich, B., Xia, H.A. and Stevens, S.R. (2007) A Randomized, Open-Label Trial of Continuous Versus Interrupted Etanercept Therapy in the Treatment of Psoriasis. Journal of the American Academy of Dermatology, 56, 598-603. https://doi.org/10.1016/j.jaad.2006.09.002

[10] Siegfried, E.C., Eichenfield, L.F., Paller, A.S., Pariser, D., Creamer, K. and Kricorian, G. (2010) Intermittent Etanercept Therapy in Pediatric Patients with Psoriasis. Journal of the American Academy of Dermatology, 63, 769-774.

https://doi.org/10.1016/j.jaad.2009.10.046 